\title{
Las prácticas socioeducativas y sus desafíos en la formación arqueológica-universitaria regional, Mendoza, Argentina*
}

\author{
Leticia Saldi \\ Ianigla; Conicet; Universidad Nacional de Cuyo, Mendoza, Argentina \\ leticiasaldi@gmail.com \\ https://orcid.org/0000-0003-0344-7185
}

Luis Mafferpa

IAE; Ianigla; Conicet; Universidad Nacional de Cuyo, Mendoza, Argentina luismafferra@gmail.com https://orcid.org/0000-0002-3966-6833

Vanina Terraza

$I A E$, Universidad Nacional de Cuyo, Mendoza, Argentina vaninavterraza@gmail.com https://orcid.org/0000-0002-7942-1005

Karina Castañar

Universidad Nacional de Cuyo, Mendoza, Argentina karinasilvana.cg@gmail.com https://orcid.org/0000-0002-3509-0363

\section{RESUMEN}

A partir de la revisión de la extensión en América Latina y la definición de las denominadas prácticas socioeducativas (PSE) que se proyectan en las universidades nacionales argentinas, analizamos los desafíos que representa esta forma de vinculación social para la novel carrera de arqueología en la Universidad Nacional de Cuyo. Para ello, contextualizamos nuestro caso de estudio situado en el norte de la provincia de Mendoza, centro oeste argentino. Realizamos un análisis de antecedentes sobre la extensión haciendo foco en aquellos momentos, conceptos y paradigmas que permitieron establecer formas igualitarias de construcción del conocimiento entre universidad y entorno. Sobre este legado, definimos las principales características de las PSE. Posteriormente, revisamos los antecedentes en cuanto al rol social y a la extensión en arqueología latinoamericana, y consideramos los casos regionales. Finalizamos exponiendo los desafíos que representan las PSE como formas integrales de extensión en la formación universitaria en arqueología y que implican redefinir la propia disciplina en cuanto al rol del profesional, su vinculación con el entorno y los sujetos sociales.

Palabras clave: relación universidadcontexto; América Latina; formas integrales de extensión; Licenciatura en Arqueología; centrooeste argentino.

Cómo citar: Saldi, L, Maferra, L., Terraza V. y Castañar, K. (2021). Las prácticas socioeducativas y sus desafíos en la formación arqueológica-universitaria regional, Mendoza, Argentina. Ciencias Sociales y Educación, 10(19), 189-217. https://doi.org/10.22395/csye.v10n19a8

Recibido: 26 de agosto de 2020.

Aprobado: 25 de noviembre de 2020. 


\section{Social and Educational Practices and their Challenges in Regional Archaeological-University Training, Mendoza, Argentina}

\section{ABSTRACT}

Starting with a review of the concept of extension in Latin-America and the definition of Social and Educational Practices (PSE) projected in Argentinian national universities, this research analyzed the challenges this form of social bonding poses for the newly created archaeology studies in Cuyo's National University. Therefore, we first contextualize our case study, located in the Mendoza province, Central-West Argentina. The study then performs a background analysis about extension focusing on those moments, concepts and paradigms which allowed the disposition of egalitarian knowledge construction way of between university and its environment. From this perspective the study defined the main PSE characteristics. Later, reviewed the precedents concerning social roles and extension in Latin American archaeology considering regional cases. Finally, the study puts forward the challenges PSE have as an integral extension form representing university education in archaeology, which implies the redefinition of the very same discipline regarding the role played by its professionals and their connection with the environment and social subjects.

Keywords: university-environment relation; Latin.America; integral extension forms; archaeology studies; Central-West Argentina.

\section{Práticas socioeducativas e seus desafios na formação arqueológica universitária regional, Mendoza, Argentina}

\section{RESUMO}

A partir da revisão da extensão na América Latina e da definição das chamadas Práticas Socioeducativas (PSE) que se projetam nas universidades nacionais argentinas, analisamos os desafios que esta forma de vínculo social representa para a nova carreira da arqueologia, na Universidade Nacional de Cuyo. Para isso, primeiro contextualizamos nosso estudo de caso localizado no norte da província de Mendoza, centro oeste da Argentina. Fizemos uma análise dos antecedentes da extensão, enfocando aqueles momentos, conceitos, paradigmas que permitiram estabelecer formas igualitárias de construção do conhecimento entre a universidade e o meio ambiente. Com base nesse legado, definimos as principais características do PSE. Posteriormente, revisamos os antecedentes a respeito do papel social e da extensão na arqueologia latino-americana, consideramos casos regionais. Concluímos expondo os desafios que a PSE como forma integral de extensão representam na formação universitária em arqueologia e que implica na redefinição da própria disciplina no que se refere ao papel do profissional, ao seu vínculo com o meio e os sujeitos sociais.

Palavras-chave: relação universidadecontexto; América Latina; formas abrangentes de extensão; Bacharel em Arqueologia; Argentina centro-oeste. 


\section{Introducción}

La arqueología se fundó como la ciencia encargada de investigar y analizar el comportamiento de poblaciones humanas pretéritas a partir de sus restos materiales, y se detuvo en aquellas que no tenían sistemas de escritura occidentalizados. Sus producciones científicas ayudaron a conocer los modos de vida de grupos de cazadores-recolectores o el surgimiento de las primeras formas de cultivo y domesticación de animales, entre otros temas. En este contexto, el lugar del arqueólogo (por lo general varón) era indiscutible y clave a la hora de producir discursos que establecieran lo que finalmente formaba parte del pasado de un grupo humano, una cultura o incluso una nación. Su rol para la sociedad contemporánea era dado, además, por su función como analista experto de las materialidades pasadas, en especial como el encargado de determinar qué objetos o lugares eran relevantes para ser conocidos y recordados por las actuales y futuras generaciones. Así, los museos o los sitios de valor patrimonial eran los contextos donde esta vinculación se concretaba. En estos, si bien primaba el objetivo de la conservación, también se presentaban exposiciones dispuestas de acuerdo con los paradigmas dominantes de cada momento y a los discursos históricos vigentes. Hasta fines del siglo XX la relación entre arqueología y sociedad se establecía en estos términos y se restringía, con algunas excepciones, a las dadas en dichos espacios.

Este papel desempeñado por la arqueología en la sociedad comenzó a resquebrajarse ya desde el último cuarto del siglo XX. Las críticas surgieron tanto desde dentro de la disciplina como desde las poblaciones indígenas contemporáneas que cuestionaron los discursos y las representaciones que se transmitían sobre ellas, así como la propiedad de los materiales expuestos y que hasta ese momento eran solo el objeto de estudio de los arqueólogos. Ello generó profundos debates basados en las siguientes preguntas: ¿A quién le pertenecen los restos arqueológicos? ¿Quién decide sobre lo que se puede exponer y cómo? ¿Cómo y con qué fines se articulan los discursos sobre el pasado? Así emergieron nuevos interrogantes que abrevaban en cuál era finalmente el rol social de la disciplina. Estas problemáticas se abordaron desde enfoques como la arqueología social latinoamericana (Vargas, 1995), la arqueología pública o comunitaria (Funari, 2002; Salerno, 2013), las arqueologías indígenas (Ayala, 2020), entre otras.

No obstante, esta emergencia de perspectivas no se vio reflejada de manera clara y generalizada en el surgimiento de nuevas metodologías de trabajo y formas de intervención social. Especialmente, no afectó la formación disciplinar en arqueología que continúa dirigida a la recuperación y análisis de materialidades para la investigación del pasado con escaso énfasis en la relación con actores y problemáticas presentes. Esto es notable en la carrera de Arqueología de la Facultad de Filosofía y Letras de la Universidad Nacional de Cuyo, en la cual los autores 
de este artículo somos docentes. Además, si bien no existen estudios exhaustivos sobre el tema, este déficit en la formación de habilidades para la inserción social de la arqueología parece ser general a escala latinoamericana, con base en lo observado por algunos estudios exploratorios (González Jaramillo, 2008; Ramundo, 2008).

Sin embargo, la conexión entre academia y entorno social no fue ni es una problemática exclusiva de la arqueología ni de su formación, sino más bien de todo el conjunto universitario desde sus inicios. ¿Cómo se transmitía el conocimiento hacia los entornos donde se ubicaban las universidades? ¿Cómo se vinculaban formalmente las distintas disciplinas, entre ellas la arqueología, a los saberes y prácticas de los sujetos sociales no universitarios? La relación universidad-sociedad tiene una importante trayectoria y ha pasado por distintos vaivenes de acuerdo con los procesos históricos mundiales, latinoamericanos y nacionales, por lo que las formas en que se ha concebido la extensión ha ido de la mano de los contextos sociopolítico y económicos de su tiempo.

Desde las últimas dos décadas del siglo $\mathrm{XX}$, los distintos países latinoamericanos se vieron atravesados por profundas problemáticas sociales, ambientales y culturales que se entrelazan con las históricas. Conflictos socioambientales desatados por la lógica extractivista; el crecimiento exponencial de la violencia de género; la visibilización de movimientos sociales que apuestan por un dinamismo respecto al género y la sexualidad; el rol de la informática, la virtualidad y la inteligencia artificial en nuestras vidas; el auge de enfermedades que amenazan a la propia especie humana en su conjunto son algunas de las grandes problemáticas que atraviesan las primeras dos décadas del segundo milenio. A su vez, estas se suman a los procesos históricos de jerarquización y exclusión social, cultural, política y económica con que se configuraron los países latinoamericanos a partir de la colonización de sus territorios.

Por lo tanto, teniendo en cuenta la formación disciplinar en arqueología y las formas en que se han concebido la extensión universitaria en América Latina y las problemáticas socioculturales político y económicas del nuevo milenio, nos centramos en conocer los aportes y desafíos que representa para la formación en arqueología una forma de extensión universitaria denominada prácticas socio-educativas a nivel regional y que se imponen para ser trabajabas en las diecinueve unidades académicas de la Universidad Nacional de Cuyo, situada en la provincia de Mendoza, en el centrooeste de Argentina.

Para ello, el artículo comienza por exponer la contextualización local de la que partimos, los conjuntos de antecedentes y fuentes relevadas. Posteriormente, le continúan tres grandes bloques. En el primer bloque analizamos el legado, muy presente en la actualidad, de la reforma universitaria de 1918 en Argentina 
y extendida hacia otros países latinoamericanos. Considerando la importancia de la extensión en esta reforma universitaria, analizamos los diversos significados de extensión y de vinculación universidad-sociedad que le sucedieron, y se hizo hincapié en los antecedentes locales que hoy, desde distintos lugares, repercuten en la formación universitaria en arqueología. Para finalizar este apartado, reflexionamos sobre un formato reciente de extensión universitaria denominado prácticas socioeducativas (PSE) o prácticas sociocomunitarias, el cual tiene un gran alcance en las universidades argentinas, así como en las locales. Este formato se presenta como guiador en la relación universidad-sociedad en la segunda década del nuevo milenio en adelante.

En el segundo apartado analizamos los principales debates que se vienen generando en la arqueología desde hace algunas décadas a escala latinoamericana. Estos conllevan a reflexionar sobre el vínculo de la disciplina con diversos actores y problemáticas actuales. Posteriormente, observamos las limitaciones a la hora de aplicar o generar nuevas formas de intervención social. Finalmente, repasamos experiencias y antecedentes en vinculación social y arqueológica en la región del norte de Mendoza.

En el tercer bloque reflexionamos sobre cómo las PSE y su propuesta interpela, influye y estimula cambios en los paradigmas hegemónicos de la formación en arqueología. En este apartado reflexionamos sobre cómo las PSE y su legado histórico, basado en el diálogo de saberes, el conocimiento coconstruido, la inserción e involucramiento de docentes y estudiantes en las problemáticas de las comunidades, implican comenzar a reconstruir la propia disciplina al reconciliar la práctica con las teorías críticas. Supone también reformular el rol de docentes y estudiantes en arqueología, ya no como los hacedores del pasado, sino como interlocutores para repensar-rehacer el pasado en conjunto e inmersos en las contradicciones del presente. En este sentido, finalizamos el artículo especificando los desafíos que representan las PSE en la formación disciplinar en arqueología.

\section{Contexto local y metodología de análisis}

En el marco de diversos procesos de movilización social en la provincia de Mendoza, la Universidad Nacional de Cuyo (Uncuyo) redactó en el 2013 su Plan estratégico 2021 y expuso, desde su inicio, la necesidad de integrar la docencia con la investigación, la vinculación y la extensión "articulando saberes y disciplinas; se involucra con la sociedad en el logro del bien común, en la construcción de ciudadanía y en el desarrollo socialmente justo, ambientalmente sostenible y territorialmente equilibrado del pueblo argentino" (Universidad Nacional de Cuyo, 2013, p. 2). Atento a las problemáticas sociales, culturales, ambientales 
y económicas de la provincia y la región de Cuyo en general, lo que se presentaba históricamente como optativo —es decir, la extensión—comenzó a plantearse bajo una política universitaria general, obligatoria y que debía adoptarse en las diecinueve unidades académicas (UA). De esta manera, las prácticas socioeducativas (PSE) cobraron gran relevancia al transformarse en parte de la currícula universitaria de sus ciento veintidós carreras de grado y pregrado.

Junto con esta transformación, en la Facultad de Filosofía y Letras (FFyL), unidad académica fundante de la propia Uncuyo en 1939, se crea la Licenciatura en Arqueología, la cual se desprende de la carrera de Historia y adopta a las PSE desde sus inicios para proponer los siguientes objetivos: "Llevar a cabo actividades de docencia y extensión que promuevan la transferencia, difusión y vinculación con la sociedad de los aportes de la Arqueología al conocimiento del pasado y a la conservación del Patrimonio cultural" (Ordenanza 55, 2019, p. 14).

El plan de estudio en Arqueología se encuadró en los marcos establecidos por el plan estratégico universitario, la Ley de Educación Nacional 26.206 (2006) y la Ley de Educación Superior 24.521 (1995), que definen a la educación como un bien público y un derecho garantizado por el Estado en donde la educación superior "debe garantizar igualdad de oportunidades, inclusión social, equidad y respeto a la diversidad" (Ordenanza 55, 2019, p. 4). Su Plan de Estudio se configuró a partir de

los lineamientos pedagógico-didácticos del Enfoque Basado en Competencias (Ord. 075/16-C.S. Uncuyo). El mismo supone focalizar la atención en los procesos de aprendizaje de los estudiantes y poner el énfasis en la articulación de saberes con situaciones concretas de la realidad. (Ordenanza 55, 2019, p. 78)

Entre las competencias generales planteadas para la Licenciatura en Arqueología, destacamos dos: i) "asumir una actitud reflexiva y crítica, generando acciones que tiendan hacia la construcción colectiva del conocimiento y transformación de la realidad" y ii) "planificar, coordinar y evaluar proyectos de intervención de relevancia social y cultural en articulación con diferentes actores sociales" (Ordenanza 55, 2019, p. 12)

Desde estos lineamientos, las PSE se destacan en dicha formación por plantearse como uno de los espacios donde la articulación entre universidad y sociedad es central y planificada desde el inicio de cualquier proyecto. Las PSE tienen un rol protagónico dentro del Plan de estudio de la carrera de Arqueología, el cual propone las siguientes expectativas de logro:

Establecer vínculos con la sociedad y sus problemáticas sociales y comunitarias relevantes de un modo activo y comprometido. [...] Establecer procesos de interacción proactivos que contribuyan con el análisis, la detección, la comprensión y solución de problemas sociales concretos del contexto en el cual desarrollará su actividad 
profesional. [...] desarrollar actitudes solidarias y comprometidas en los ámbitos en los que se desempeñará [el futuro o futura profesional. [...] Desarrollar la capacidad de generar propuestas pedagógicas comprometidas con el medio social, en las cuales se profundicen los saberes curriculares propios de su formación profesional de base. (Ordenanza 55, 2019, p. 25)

En dicha carrera, las PSE tenían previsto ejecutarse a partir del 2020. Sin embargo, su ejecución fue impedida como producto de la crisis mundial sanitaria desatada por la COVID-19. Para evitar la propagación del virus en Argentina, se decretó el aislamiento social preventivo y obligatorio (Decreto 297, 2020, y sucesivos), lo que implicó, entre otras cosas, el cierre físico de todas las instituciones, entre ellas las educativas, y la imposibilidad absoluta del encuentro físico entre estudiantes, docentes y poblaciones locales. El tiempo de distanciamiento social propició, sin embargo, el momento necesario para indagar sobre estas prácticas en términos históricos y contextuales. Esto nos permitió conocer el o los legados que recupera y trae al presente en sus distintas escalas espaciales, latinoamericanas, argentinas y regionales.

Para ello, nos propusimos trabajar en el relevamiento y lectura crítica sobre tres aspectos: el primero tiene que ver con los antecedentes en torno a la extensión en América Latina y a las prácticas socioeducativas propuestas en Argentina; el segundo se preocupa por la sistematización de antecedentes relativos a la problemática de extensión en las disciplinas arqueológicas latinoamericanas y argentinas; y el tercero consiste en el relevamiento de distintas fuentes primarias relativas al conjunto de políticas universitarias a nivel nacional, provincial y de la propia carrera de Arqueología (normas, planes estratégicos y planes de estudio) ${ }^{1}$. El relevamiento y sistematización en estos tres conjuntos de antecedentes y de fuentes estuvo acompañado de cuatro entrevistas virtuales exploratorias a referentes de las PSE en la Uncuyo que nos ayudaron a entender y ordenar estas fuentes y antecedentes. El análisis de todo el cuerpo de antecedentes nos permitió conocer los legados de las PSE, su propia propuesta e implicancias, los últimos debates en arqueología respecto a su formación y vinculación con el entorno social, así como la consideración de los desafíos profundos que las PSE representan para la propia formación disciplinar.

Los documentos relevados fueron el Acuerdo Plenario 711 (2009) y el Acuerdo Plenario 811 (2012) del Consejo Interuniversitario Nacional, Programa de fortalecimiento de la extensión universitaria en las universidades públicas argentinas; la creación y reforma del Plan de estudios de la carrera de Licenciatura en Arqueología (Ordenanza 55, 2019), la aprobación del proyecto de reglamentación de la Ordenanza 07 (2016) del Consejo Superior de la Uncuyo, la Ordenanza 75 (16) del Consejo Directivo de la FFyL en donde se implementan, entre otras cosas, las PSE como obligatorias para todas las modificaciones en los planes de estudio y nuevas carreras. También relevamos el Plan estratégico 2021 de la Uncuyo. 


\section{Principales legados de la extensión en América Latina y presentación de las PSE}

En Argentina, en circunstancias de apertura de la democracia y bajo la promulgación del voto universal (excluyendo a las mujeres adultas) y obligatorio en 1916, se promovió, en el ámbito universitario y desde el sector estudiantil, la reorganización de las instituciones universitarias que para ese entonces eran manejadas por el claustro docente y por el clero, y que se articulaban en tres universidades nacionales (Córdoba, Buenos Aires y La Plata) y dos provinciales (Tucumán y Santa Fe). En el Primer Congreso Nacional de Estudiantes Universitarios del 11 de abril de 1918, se sentaron las bases de la reforma universitaria. Entre ellas estaban la autonomía universitaria respecto del gobierno democrático, así como la participación de profesores, estudiantes y graduados en el gobierno y la gestión universitaria. Bajo estos pilares se concebía la universidad como obligada a "ir hacia el pueblo para conocer sus problemas, ilustrarlo y colaborar en la creación de normas que lo protejan contra la violencia y el privilegio" (Facultad Regional Mendoza, Universidad Tecnológica Nacional, 1995, p. 11). Asimismo, se reconocían los déficits de la extensión y las dificultades para su implementación, por lo que también se advertía el tiempo y la dedicación extra en el proceso de enseñanza-aprendizaje. Se planteaba también una alianza necesaria entre la universidad y el sector obrero, y se consideraba que la universidad debía estar "abierta al pueblo".

Las repercusiones de la reforma universitaria se dieron en todo el país, lo que provocó un proceso de renovación en las universidades ya creadas, pero también generó la apertura de nuevas universidades. En el caso regional, el Movimiento de Estudiantes Secundarios de Mendoza, San Juan y San Luis, gestionó la creación de la Universidad Nacional de Cuyo, la cual se inauguró en 1939 bajo el Decreto 26.971 del poder ejecutivo nacional (Facultad Regional Mendoza, Universidad Tecnológica Nacional, 1995). Meses más tarde se creó la Facultad de Filosofía y Letras (donde setenta y ocho años después se crea la Licenciatura en Arqueología). A nivel internacional, la reforma universitaria de 1918 tuvo importantes repercusiones en Perú, México, Chile, Venezuela y Uruguay durante las primeras décadas del siglo XX. En este contexto, la extensión se pensaba como un eje articulador entre la creación del conocimiento, los grandes problemas nacionales y las necesidades de los sectores populares (Tommasino y Cano, 2016).

Sin embargo, el movimiento reformista tanto nacional como latinoamericano atravesó distintos vaivenes de acuerdo con los contextos nacionales e internacionales y a las formas diferenciales de entender la extensión; una de ellas se basa en la difusión del conocimiento al resto de la sociedad. La lógica transferencista se convertía, como advierte Gimena Vázquez (2016), en una lógica subyacente: "en donde hay 'un experto' que tiene un conocimiento determinado 
y un 'beneficiario' que recibe parte de ese conocimiento o ciertos beneficios de ese conocimiento" (p. 13). Esta lógica transferencista existió desde las primeras formas de entender la extensión, en donde la universidad era la hacedora del conocimiento y la extensión consistía en la difusión del mismo al resto de la sociedad (Piazzini Suárez, 2014).

Frente a esta forma de concebir la relación universidad-entorno social, distintos filósofos, pedagogos y cientistas comenzaron a distanciarse de esta postura y a pensar en otras formas de vinculación, y Paulo Freire fue uno de sus mayores críticos. Para él, el principal problema de este tipo de acción era la invasión cultural hacia la comunidad, es decir, la imposición de valores socioculturales y económicos de contextos ajenos a los ámbitos locales. Su crítica fue acompañada por múltiples pensadores latinoamericanos ${ }^{2}$ que comenzaron a fomentar diversos paradigmas y metodologías que promovieran un vínculo horizontal entre universidad y sociedad. Fue entonces que, bajo un contexto de revoluciones sociales y de fuertes críticas al sistema capitalista tanto en América Latina como en Argentina, se formularon en términos pedagógicos los paradigmas de educación popular (Ortiz y Borjas, 2008) postulada por Paulo Freire (1994 [1970]; 1999 [1967]; 2002 [1992]); la teología de la liberación (Dussel, 1973); la investigación-acción participativa propuesta (Fals Borda y Rodriguez Brandao, 1987; Fals Borda y Anisur, 2007) y la comunicación alternativa propuesta como recursos pedagógicos para reemplazar el habla (Deliyore-Vega, 2018), entre otras. Concretamente, la Facultad de Antropología Escolar, ubicada en la provincia de Mendoza, fue una institución clave para la generación de pedagogías atentas a la vinculación con la sociedad. Esta fue creada por el Gobierno provincial el 28 de agosto de 1963, donde se dictaban las carreras de Psicología, Pedagogía y Educación Diferencial. En este sentido, fue pionera en los procesos de enseñanza-aprendizaje vinculados a la educación popular y a la "construcción colectiva del conocimiento entre docentes, no docentes y estudiantes" (Facultad de Antropología Escolar de Mendoza, 2012).

Si bien estos paradigmas tuvieron un importante desarrollo a nivel latinoamericano, nacional y regional, muchos de ellos se vieron ofuscados ante el violento avance de los planes relacionados con la Operación Cóndor, que se impusieron en toda Latinoamérica. En este contexto, las universidades fueron un foco importante de represión estudiantil y docente, así como de socavamiento de todo proyecto vinculado a la educación popular (Erreguerena, 2020). En el caso mendocino, y en el marco del golpe de Estado perpetrado en 1976 a nivel nacional, este proceso se evidenció con el cierre abrupto de la Facultad de

2 Fabio Erreguerena (2020) destaca los aportes de José Carlos Mariátegui, Juan Antonio Mella, Leopoldo Zea, Aníbal Quijano, Augusto Salazar Bondy, Isabel Larguía, Darcy Ribeiro, Heleieth Saffioti, Enrique Dussel, Eva Giberti, Orlando Fals Borda, Silvia Rivera Cusicanqui, Rodolfo Stavenhagen, Agustín Cueva, Pablo González Casanova, Arturo Roig, Elizabeth Jelin. 
Antropología Escolar el 1 de abril de 1977 y la desaparición y exilio de muchos de sus docentes y estudiantes. Esta situación hoy se recuerda y conmemora por los sobrevivientes, sus hijas e hijos y se continúa sobre todo en la Facultad de Educación Elemental de la Uncuyo (figura 1).

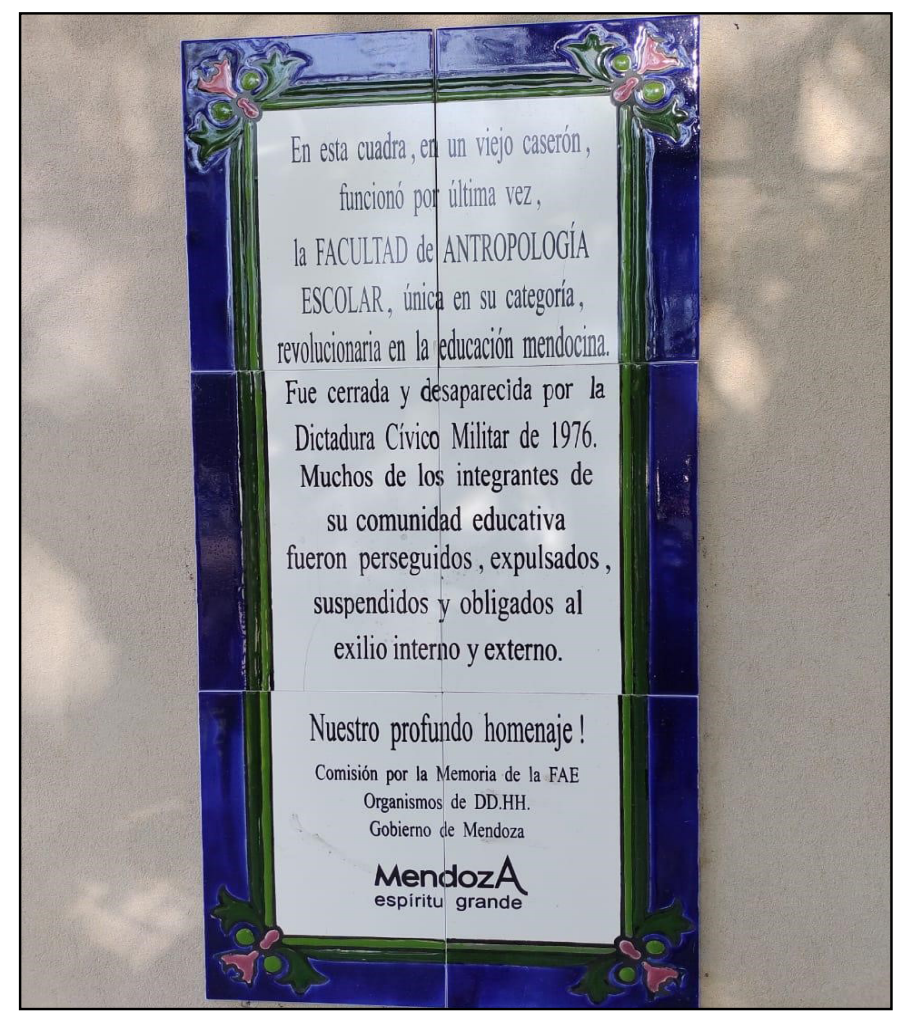

Figura 1. Placa conmemorativa3

Fuente: Leticia Saldi, archivo personal, 2021.

Con las reaperturas de las democracias se da un paradojal (Briones, 2005) y perverso (Dagnino, 2004) proceso de reconocimiento de derechos étnicos, sociales y civiles, así como de formas de participación descentralizadas, introducción de lógicas neoliberales, flexibilización laboral y de promoción del individualismo y las lógicas de consumo. Como destacan Tommasino y Cano (2016), en este escenario, los programas de extensión en las universidades tomaron una amplia gama de significados desde las formas de educación popular hasta formas más

3 Esta placa fue colocada en el mes de agosto de 2013 en el quincuagésimo aniversario de la creación de la FAE por la Comisión de la Memoria de la Facultad de Antropología Escolar (FAE), el Ministerio de Desarrollo Social y Derechos Humanos a través de la Dirección de Promoción de Derechos Humanos (Prensa Gobierno de Mendoza, 2013) 
mercantiles de generación de servicios y, por ende, de recaudación monetaria por parte de las universidades.

El término extensión se convirtió en un significado vacío, propio de la construcción hegemónica del poder (Laclau y Mouffe, 2011) y que algunos autores (Gonzalez y Gonzalez, 2003 y 2006, citados en Ortiz-Riaga y Morales-Rubiano, 2011) las han ordenado en tres grandes modelos: i) el tradicional, que se basa en la transmisión vertical del saber desde las universidades hacia la sociedad; ii) el economicista, en donde la universidad se la concibe como una empresa más; y iii) el integral, en donde se acentúa la función democratizadora de la universidad y se apunta a la solidaridad y misión transformadora de los pueblos.

Asimismo, en este contexto marcado por el desarrollo de políticas neoliberales, la extensión perdió jerarquía en relación con los otros dos aspectos clave que hacen a la universidad, es decir, la docencia y la investigación. Como advertían varios autores y autoras citados en Ortiz-Riaga y Morales-Rubiano (2011), la extensión por estas décadas, es decir, entre 1990 y 2000, tuvo un carácter muy heterogéneo y marginal respecto a la investigación y la docencia.

Sin embargo, la presencia de los nuevos movimientos sociales, o estallidos sociales como fue en Argentina el 2001 —donde los sectores medios reclamaban una renovación profunda de las instituciones estatales y de las formas de participación política bajo el lema "que se vayan todos" - replantearon y reactualizaron las temáticas relativas a la acción colectiva, las formas alternativas de resolución de conflictos y de participación social ciudadana (Giarracca, 2002). Estos movimientos no solo se plantearon en el ámbito de las ciudades (Svampa, 2008), sino también en los espacios rurales y cordilleranos (Giarracca y Bidaseca, 2001). Sus poblaciones se movilizaron espontáneamente frente a la destrucción de sus entornos, principalmente por la minería a gran escala como sucedió en Mendoza (Wagner, 2014), los proyectos hidroeléctricos, la agricultura intensiva asociada a las commodities (Giarracca y Teubal, 2008, 2013)

En este contexto de movilización social, las universidades argentinas y latinoamericanas, apoyadas por gobiernos que apuntaban a la justicia social, comenzaron a replantear su propia posición en el entramado sociocultural y a repensar una práctica de extensión que socave la lógica transferencista, economicista y proponga formas de retroalimentación entre universidad y sociedad (Lischetti, 2013).

Un ejemplo claro de ello fue la propuesta de la Universidad de la República en Uruguay, por medio de la institucionalización del espacio de formación integral (Tommasino et al., 2010). Enmarcándolo dentro de una segunda reforma universitaria, Tommasino y Rodriguez (2013) reflexionan sobre sus bases y 
desafíos y conciben que la extensión "debe interactuar en el acto educativo y formar parte de la cotidianidad del mismo" (p. 85). Por lo tanto, ya no debía ser algo ad-hoc que impulsaran docentes o estudiantes interesados ni por espacios desarticulados, sino una política universitaria institucionalizada que comenzara a establecerla desde el aparato jurídico universitario. En este sentido, advierten Lischetti, Paoletta y Sander (2019): "el lenguaje jurídico es una palabra creadora en tanto hace existir lo que se anuncia" (p.52).

En esta misma sintonía, desde el 2009 en Argentina, el Consejo Interuniversitario Nacional y las comisiones directivas de las distintas universidades nacionales publicaron resoluciones que institucionalizaron y jerarquizaron la extensión integral y la ubicaron como pilar, junto con la docencia y la investigación, bajo denominaciones tales como prácticas sociocomunitarias o prácticas socioeducativas ${ }^{4}$. Estas van de la mano con la formación integral planteada en la Universidad de la República. Por lo tanto, las PSE, o también prácticas sociocomunitarias (PSC) (Macchiarola, 2016) o espacios de formación integral como se denomina en Uruguay, se asientan sobre la base de un paradigma crítico de la educación (Paulo Freire) y recupera las metodologías de la investigación-acción iniciadas por Fals Borda y Rodriguez Brandão en la década del setenta y la ecología de saberes proyectada por Boaventura de Sousa Santos. Este último autor considera que el conocimiento no está ni en el docente universitario ni en el sector popular, sino en la interacción entre ambos (Sousa Santos, 2010, 2012).

En términos generales, y como apuntan Tommasino y Rodriguez (2013), este tipo de extensión concibe la complejidad de la realidad como indisciplinada. Esto implica necesariamente la construcción interdisciplinaria y colectiva del conocimiento poniendo en diálogo los saberes de docentes, estudiantes, organizaciones de la sociedad civil y demás actores sociales y "conformando una red de saberes, una ecología de saberes que contribuye a la transformación participativa de la realidad" (p. 100).

En consonancia con los postulados de Tommasino y Rodriguez (2013), Viviana Macchiarola (referente de la extensión en la Universidad de Río Cuarto, centro argentino) reconoce que las prácticas sociocomunitarias implican cambios medulares en tres importantes ejes: i) en las formas de concebir el conocimiento, ii) en los modos de aprendizaje y iii) en el diseño de los currículum. En cuanto al primer pilar, la autora afirma que las PSC rompen con la postura tradicional donde el conocimiento está en el plantel docente para ser transmitido al alumnado. En este sentido, las PSC no solo dan paso y autoridad a las voces del estudiantado, sino también al conocimiento aportado desde los territorios donde pobladores,

$4 \quad$ En el 2009, el Consejo Interuniversitario Nacional aprueba el Programa de Fortalecimiento de la Extensión Universitaria en las Universidades públicas argentinas (Acuerdo Plenario 711, 2009) y en el 2012 aprueba el Plan Estratégico 2012-2015 (Acuerdo Plenario 811, 2012). 
mujeres, niños, varones, ancianos y ancianas tienen conocimientos para asumir el rol enseñante, lo cual habilita la circulación de saberes que son compartidos y resurgidos en nuevos conocimientos (Tommasino y Cano, 2016). La figura del docente deja de ser el único lugar de transmisión del conocimiento, para ser un posibilitador, un organizador, un coordinador esencial, así como un aprendiz de los contextos.

En este entramado abierto al ejercicio de la horizontalidad, el conocimiento es situado y surge de la práctica. En este sentido, es dialógico. Ya no solo se genera en las aulas tradicionales, sino también en los espacios extramuros del aula. Esto implica, como segundo eje, un aprendizaje situado y producido a partir del intercambio con y en el contexto. Ello supone desarrollar competencias como "saberes en acción, como praxis que articula conocimiento y práctica" (Macchiarola, 2016, p. 5). Por lo tanto, el aprendizaje no solo se refiere a la incorporación de nuevos saberes, sino al desarrollo de capacidades para actuar en contexto y articular lo práctico con lo teórico desde el inicio mismo de la carrera y no después de esta, como generalmente sucede.

Por último, pero también en relación con los ejes anteriores, las PSC o PSE se asientan sobre una "nueva forma de pensar y organizar la universidad" (Macchiarola, 2016, p. 5). Si partimos de la base de que el conocimiento se genera en y a partir de los contextos y de las problemáticas socioculturales, económicas y ambientales locales, el saber es multi e interdisciplinario, así como multiactoral y de multisaberes. Esto excede el paradigma tradicional del conocimiento partido que se divide en disciplinas y subdisciplinas, unidades académicas, instancias de docencia-investigación-extensión, y lleva a la articulación permanente entre cada estamento. Desde el establecimiento de puentes, conexiones, la currícula de cada carrera y materia se plantea a partir de ejes problemáticos. Esto quiere decir que el currículo ya no es cerrado estático ni presupone primero la teoría y luego la práctica, sino que es capaz de adaptarse a las problemáticas situadas. Por lo tanto, es flexible, predispuesto a los espacios abiertos y "con una secuencia no lineal de aprendizajes" (Macchiarola, 2016, p. 5).

Por lo tanto, y desde esta perspectiva, la inclusión de las PSE no se trata de una materia más que se suma a la secuencia de materias a aprobar para finalizar una carrera universitaria, sino que implica profundos cambios en las formas de concebir y transmitir conocimientos y saberes, lo cual lleva sobre todo a trabajar desde otros paradigmas en ciencia y educación y hasta otras ontologías o realidades plurales, en las que urge resituar a la universidad en ellas. Como apunta Piazini Suárez (2014) introducirse en un proceso de vinculación con la sociedad implica, "más que 'llevar' la universidad a otros espacios, se 'traiga' 
la universidad y la involucre conscientemente como actor de las dinámicas geopolíticas" (Piazzini Suárez, 2014, p. 30) locales, regionales y globales.

Bajo estos lineamientos, las distintas universidades argentinas comenzaron un importante proceso de institucionalización en el que la extensión recobró un rol protagónico en la formación universitaria5. ¿Pero qué implica su implementación en la formación arqueológica universitaria regional? ¿Cómo se articula con los debates acerca de la propiedad de los restos patrimoniales y de las formas de construcción del pasado? ¿Desde esta perspectiva, cómo se reconsidera el rol del arqueólogo y de la arqueóloga?

\section{Dehates sobre la relación entre arqueología y sociedad en el contexto latinoamericano}

La aplicación de un programa de prácticas socioeducativas, en el marco de la formación en arqueología, supone afrontar un desafío extra dado por la incierta definición de cuál es finalmente su rol social. Situados en el contexto de acción latinoamericano, esta definición presenta matices particularmente problemáticos. A grandes rasgos podemos distinguir dos perspectivas desde donde la disciplina busca legitimidad: una optimista con el avance científico y el descubrimiento del pasado, y otra crítica (Angelo, 2019). La primera, neopositivista, define su agenda con base en la actualización metodológica o aplicación de nuevas técnicas para la resolución de problemas estrictamente relacionados a la descripción del registro arqueológico. Entiende, por tanto, que su rol social se basa en la transferencia de conocimientos sobre el pasado y la conservación del patrimonio. Si bien esta línea presenta una continuidad con la función clásica de la disciplina que se señaló en la introducción, es también la más prolífica en cuanto a producciones científicas escritas aun en la actualidad (Acuto, 2019). Su modo de intervención social presenta, sin embargo, algunos problemas a considerar. Por empezar, utiliza una definición unívoca de pasado

\footnotetext{
En el 2009 la Universidad de Río Cuarto en la provincia de Córdoba, bajo la Resolución 322 (2009) , el Consejo Superior institucionaliza las prácticas sociocomunitarias. En el mismo año, y desde la creación de la propia Universidad Nacional de Avellaneda, se implementa el Trayecto de Trabajo Social Comunitario como instancia obligatoria en todas sus carreras de grado y pregrado. Un año más tarde, en el 2010, la Universidad de Buenos Aires (Resolución 520, 2010) estableció el Programa de Prácticas Sociales Educativas obligatorias a partir del ciclo lectivo 2013. En el 2011, la Universidad de La Pampa avanzó sobre el Programa de Prácticas Comunitarias (Resolución 297, 2011) en donde concibe el carácter voluntario desde el 2012 y obligatorio a partir del 2017 (Erreguerena, 2020). También en este año, la Universidad Nacional de Mar del Plata (Ordenanza 1747, 2011) incluye a las PSE en la currícula de todas sus carreras de grado y pregrado. La Universidad Nacional de Río Negro incluye en su currícula los Programas de Trabajo Social (UNRN R018, 2012) . En el 2016, le llega el turno a la Universidad Nacional de Cuyo que a partir de su Ordenanza 75 (2016, art. 4) del Consejo Superior postula a las PSE como obligatorias al momento de actualización de carreras o creación de nuevas. En el 2018, la Universidad Nacional del Centro formaliza el sistema de prácticas socioeducativas (Resolución 7381, 2018 C. Superior) y en el 2019, la Universidad Autónoma de Entre Ríos, bajo la Ordenanza 128 (2019) CS aprueba la creación de prácticas educativas territoriales (PET) para todas sus unidades académicas. Asimismo, la Universidad de La Plata se encuentra en un proceso de experiencias piloto en este sentido (Erreguerena, 2020, p. 6).
} 
y patrimonio que es hermética al diálogo con otro tipo de saberes, por lo que produce relaciones sociales que son por naturaleza asimétricas.

Con base en un cuestionamiento a esta primera línea, emerge la perspectiva crítica. Podemos hallar los primeros antecedentes en la arqueología social latinoamericana que surge en la década de los setenta y que se basa en una posición teórica marxista y el materialismo histórico. Esta se consolida a partir del Manifiesto de Teotihuacán (Lorenzo et al., 1979), donde se plantean los lineamientos teóricos. La preocupación principal de la arqueología latinoamericana es buscar una unión entre la investigación científica, la producción de conocimiento y la acción política, por lo que también se la denomina "arqueología comprometida". Esta vertiente disciplinar se desarrolló gracias a la labor de arqueólogos y arqueólogas como Luis Guillermo Lumbreras (peruano), Mario Sanoja (venezolano), Iraida Vargas (venezolana), Luis Felipe Bate (chileno), Julio Montané (chileno), entre otros.

En términos generales, estos autores conciben la arqueología como una ciencia social y la práctica arqueológica como la acción en múltiples campos de la vida social: el académico, el de la gerencia de recursos culturales y, fundamentalmente, en la educación (Vargas 1995). "En este último ámbito radica la esencia de la arqueología social, pues no plantea el conocimiento con fines meramente contemplativos sino para ser usado en la transformación social" (Vargas, 1995, p. 75). De esta manera, se parte de la premisa de que la recuperación, conservación y valoración de los bienes arqueológicos demanda la participación comunitaria, la incorporación de la comunidad que se encuentra en el medio cultural y social donde se desarrollan proyectos arqueológicos (Vargas, 2006).

Más recientemente, la problematización se ha dado en diálogo con etnografías y actores locales, con el objetivo de una descolonización de la disciplina. Los debates han reflexionado sobre la problemática relación de la arqueología con entidades políticas como los Estados o con el capital económico en el marco de la denominada "arqueología de contrato". En especial se ha cuestionado cómo contribuye la disciplina a la construcción de relatos coloniales o nacionales, la instauración de emprendimientos extractivistas, así como la activación de identidades o a la patrimonialización de objetos o lugares a integrar en la industria turística; ¿y todo ello a quién beneficia? (Funari, 2002; Gnecco y Dias, 2015; Londoño, 2016; Silva, 2015; Tantaleán, 2019).

Finalmente, se ha discutido también cuáles son los actores y colectivos con los que es preciso trabajar. De esta manera, se problematiza la complejidad de su conformación y la posible emergencia de componentes reaccionarios (GonzálezRuibal, Alonso González y Criado-Boado, 2019). En este sentido, rescatamos la propuesta de que estos colectivos deben construirse con base en relaciones 
concretas de integración y a razón de problemáticas sociohistóricas locales y reivindicaciones específicas (Haber, 2019; Londoño, 2019). Así, también se ha procurado cuestionar la estigmatización de minorías o mayorías postergadas, ya sean indígenas, campesinas, obreras, mujeres, identidades de género diversas, entre otras (Acuto, 2019; Ugalde, 2019). Además, se ha considerado la necesidad de contemplar la existencia de entidades no humanas que conforman colectivos heterogéneos y suponen modos de relacionamiento distintos a los dados desde las lógicas modernas (Haber, 2011), lo que abre el juego a que sean otros seres, además de la especie humana, los que tienen capacidad de acción, conocimiento y formas de aprender.

La forma de acción se plantea con base en procesos participativos con la comunidad, pero aún se cuestiona cuál es finalmente el rol y las responsabilidades que deben asumir los profesionales en estas interacciones. Se remarca que estos roles deben ser siempre contextualmente definidos. Así, los objetivos generales ya no apuntan a la transferencia de conocimientos o conservación del patrimonio, sino a la búsqueda de justicia social y reivindicación de derechos asociados, especialmente, a la autodeterminación o a la propiedad de la tierra. Al mismo tiempo, se busca construir narrativas que incorporen, desde lo local, historias marginales o de resistencias que interpelen la exclusión y permitan construir proyectos de futuro por fuera de la univocidad neoliberal. En este sentido, se destacan las posibilidades de aprendizaje más que de enseñanza supuestas en estas articulaciones (Angelo, 2019; Haber, 2019; Londoño, 2019).

En estas intervenciones, la función de los arqueólogos puede restringirse al análisis experto de bibliografía o materialidades, pero con el objetivo de acompañar demandas de grupos postergados. Un ejemplo de ello se da en el suroccidente de Colombia, donde el pueblo indígena Nasa fue negado como artífice del complejo arquitectónico de Tierradentro. Los discursos oficiales lo caracterizaban como un pueblo beligerante que se resistió a la conquista y que habría llegado a la zona luego de vencer a los verdaderos constructores de las ruinas que hoy constituyen un parque arqueológico. El relato hegemónico sobre ellos convertía en ilegítimos sus reclamos de autodeterminación en las tierras que ocupaban y los sitios arqueológicos. Hasta ese momento, la arqueología cumplía una función en la construcción del Estado, lo que generó una ruptura entre las comunidades indígenas actuales y su pasado. No obstante, desde fines de la década de 1990, una serie de trabajos arqueológicos demostró que la propuesta que desligaba a los Nasa de Tierradentro era insostenible empíricamente. Si bien dicho trabajo arqueológico se mantuvo dentro de lo estrictamente disciplinar, lo hizo en función de los intereses de la comunidad. Al mismo tiempo, acompañó la lucha del pueblo Nasa que se desarrolló en términos políticos y sociales mucho más allá de la intervención arqueológica (Londoño, 2011, 2019). 
En otros casos, el papel de la arqueología no se encuentra restringido por la especificidad de su experticia. En este sentido, los roles posibles son más amplios y resultan de su participación en procesos colaborativos, donde se definen prácticas específicas relacionadas con acciones políticas, educativas, patrimoniales, entre otras. Este enfoque es característico, por ejemplo, de las denominadas "arqueologías indígenas", esto es, un conjunto de perspectivas diversas que se distinguen por la construcción de una arqueología con, por y para los pueblos indígenas, así como por proponer líneas de trabajo que apuesten por su descolonización y la construcción de metodologías colaborativas (Ayala, 2020).

Las reflexiones también han girado respecto al rol de los museos. Como advertimos en la introducción, su función se asoció tradicionalmente a la preservación de objetos que los propios arqueólogos consideraban de valor arqueológico o etnográfico. Sin embargo, el comienzo del siglo XXI marcó un quiebre en varios sentidos al tipo de exposición decimonónica que venía sosteniéndose en la mayoría de las instituciones. Por un lado, surgieron cuestionamientos sobre qué tipo restos era ético exponer. Un ejemplo claro son los restos humanos reclamados por comunidades actuales, que en muchos casos abordaron procesos de restitución (ver por ejemplo Lazzari et al., 2011); mientras que en otros casos las demandas no fueron reparadas, como es el caso de la región de Cuyo (Jofre, 2020). Otro aspecto relevante fue la exigencia de actualización de las formas de exposición y comunicación que estuvo motivada por fines pedagógicos y más comúnmente por la urgencia de transformar al museo en un lugar de recreación atractivo para los visitantes. Esta transformación en la función social del museo trajo aparejado el peligro de reproducir estereotipos de alteridad con efecto de desempoderar a los colectivos en sus disputas actuales (Londoño, 2019).

\section{Aplicaciones de la extensión en arqueología y antecedentes regionales}

A pesar de esta extensa producción crítica, la mayoría de los trabajos revisados se sostienen en el desarrollo teórico. Esto ya se le señalaba a la pionera arqueología social latinoamericana, que si bien implicaba una profunda revisión de categorías e interpretaciones, no proponía una nueva metodología (Jackson, Troncoso y Salazar, 2012). Un motivo posible ante la ausencia de una propuesta metodológica radica en que las experiencias sobre las cuales se quería reflexionar son aún escasas o están en desarrollo. Otro motivo que se complementa con el primero tiene que ver con que una parte de las interacciones de la arqueología con su contexto social de acción se da en los términos de la extensión clásica, es decir, la transferencista.

Al explorar la producción bibliográfica de los últimos veinte años que se enmarca en la arqueología pública, se observa que gran parte de ella se corres- 
ponde a propuestas de extensión fundamentalmente dirigidas a la recuperación, investigación, conservación o puesta en valor patrimonial de un sitio arqueológico (Romero et al., 2004), una colección museográfica, un archivo (Funari y Carvalho, 2014), una reserva natural protegida (Degele, 2016), entre otros, o al desarrollo de propuestas de contenidos, estrategias y experiencias pedagógicas de transferencia (en general áulicas o museográficas). Mencionamos el caso del Programa de Arqueología Pública del Museo de Antropología (FFyH, UNC), cuyas actividades extensionistas en diferentes comunidades se han centrado en trabajos de arqueología de rescate, restitución de restos humanos, dictado de charlas y talleres y la generación de un proyecto audiovisual (Zabala y Fabra, 2012). Estas tareas se basan en el concepto de educación patrimonial, considerada como "una estrategia didáctica que pretende promover una visión a largo plazo de lo que significa el patrimonio, de modo que se conserve como testimonio para las generaciones futuras" (Zabala, Roura y Fabra, 2006, p. 3). Además de este último caso, entre las experiencias que atienden al vínculo arqueología-educación, señalamos aquellas realizadas en Jujuy, Argentina (Montenegro, 2012), en Taltal, Chile (Salazar et al., 2020) o en Campinas, Brasil (Funari y Carvalho, 2014), entre otros.

Esta tendencia se replicó recientemente en un simposio sobre arqueología pública realizado en el XX Nacional de Arqueología Argentina (Montenegro, Zabala y Pupia, 2019). Si bien algunos trabajos se adscribieron a marcos teóricos críticos o incluyeron alguna forma de intercambio de saberes, solo unos pocos presentaron metodologías colaborativas o realizaron reflexiones teóricas con base en prácticas concretas y de este tipo. No es nuestra intención valorar negativamente estas contribuciones, sino señalar las dificultades que supone implementar nuevas formas de vinculación social desde la arqueología.

Acercándonos al centrooeste argentino, en especial al norte de la provincia de Mendoza, la generación de conocimiento arqueológico ha estado enmarcada en la Facultad de Filosofía y Letras de la Universidad Nacional de Cuyo, a través de instituciones como el Instituto de Arqueología y Etnología del Departamento de Historia y, desde 1961, por medio de un museo que, desde el 2007, pasó a depender del decanato y del Museo "Prof. Salvador Canals Frau". Este ha sido uno de los lugares de conservación e investigación de colecciones arqueológicas que se consideran relevantes para la región y que durante los últimos años ha buscado abrirse a la comunidad con base en un "guión [sic] más antropológico, más centrado en la diversidad" (P. Cahiza, comunicación personal, 21 de julio de 2020).

Desde este ámbito, la primera experiencia educativa que buscó un acercamiento entre la arqueología y la comunidad data de mediados de la década de 
1990. Entonces, una serie de trabajos exploratorios permitieron identificar falencias en la enseñanza de la historia indígena (Durán et al., 1990, 1991). Con base en este diagnóstico, en 1996 comenzó a realizarse un taller de arqueología destinado a niños y niñas denominado arqueojuegos (Chiavazza y Cortegoso, 1997; Chiavazza, 2003). Este inició en la FFyL, pero se desarrolló más propiamente en el Museo del Área Fundacional, perteneciente al municipio de capital, Mendoza. Se ha sostenido de manera ininterrumpida por más de veinte años, incluso hasta la actualidad. Si bien se trata de una experiencia netamente pedagógi$\mathrm{ca}$, algunas de sus características la hacen un antecedente interesante de las PSE en relación con la arqueología, especialmente sus objetivos estuvieron fundados en un análisis de la realidad y buscaron modificarla. Este tipo de experiencias didácticas fueron comunes en el país a partir del final de la década de 1990, lo que hace de los museos un espacio fértil para su desarrollo.

En el año 2019, el Museo Canals Frau, el Instituto de Arqueología y Etnología y la Secretaría de Extensión Universitaria de la facultad organizaron el I Encuentro sobre la Dimensión Social de la Arqueología: Arqueología ¿Para Qué? y ¿Para Quién?. Allí se presentaron trabajos relacionados con la práctica arqueológica y su relación con las comunidades. Entre estas exposiciones destacaron dos: "Arqueología pública en Barrancas-Maipú" (2013) y "Valoración y uso social del patrimonio arqueológico. Diálogo entre arqueologxs [sic] y las comunidades del Valle de Uco" (2011), los cuales fueron financiados a partir de las convocatorias a proyectos de extensión universitaria Mauricio López y Gustavo Kent.6

En cuanto a los proyectos realizados en Barrancas, departamento de Maipú, se tomaron como base los trabajos arqueológicos realizados por el equipo de investigación en el año 2009 en esa localidad (Acuña et al., 2015). Se llevaron adelante dos proyectos durante los años 2013 y 2014. Su objetivo fue fortalecer la identificación de recursos locales patrimoniales que permitieran un desarrollo sostenible a partir de la experiencia de arqueología pública y experimental en Barrancas. Entre las actividades principales del proyecto, se realizaron charlas, talleres y demás tareas arqueológicas donde los alumnos de la escuela rural participaron de prospecciones y una excavación. También se elaboró un circuito turístico (Lucero et al., 2014).

El caso del proyecto Valoración y uso social del patrimonio arqueológico se desarrolló durante el año 2011 en una escuela rural de Tupungato (Araujo et al., 2014). Los resultados satisfactorios generaron la demanda de la escuela albergue

Estos proyectos fueron financiados por la Secretaría de Extensión y Vinculación de la Uncuyo, en donde se promueven proyectos de extensión que incorporen el diálogo de saberes y el conocimiento coconstruido entre docentes y estudiantes. Sus convocatorias han sido, por más de once años, un importante antecedente de las PSE en la Uncuyo. Hoy en día esta es una de las formas por las cuales se canaliza un proyecto de PSE en cualquiera de las facultades que conforman dicha universidad. 
n. 8-593 Yapeyú de la localidad de La Jaula-San Carlos, quienes buscaban construir un museo en su escuela. Como producto de este interés, en 2012 comenzaron los trabajos en ese departamento sin financiamiento, pero continuaron los talleres y el diálogo permanente entre estudiantes de la universidad y la comunidad. En el año 2013, con apoyo de los proyectos de inclusión social de la Uncuyo, se realizaron talleres interdisciplinarios donde participaron estudiantes y docentes de diversas disciplinas como arqueología, historia, geografía, turismo, diseño, museología, entre otras. En el año 2015 y con financiamiento del proyecto de Mauricio López Museo regional comunitario El Diamante. Articulando saberes fortaleciendo la identidad, se realizó la inauguración del museo. El objetivo de este último proyecto fue lograr la consolidación del museo regional como un espacio dinámico de investigación-acción, para generar herramientas destinadas al desarrollo de proyectos interdisciplinarios que hicieran efectiva la articulación de saberes entre la comunidad y la universidad. Asimismo, se buscó generar un proyecto educativo que incorporara al museo como herramienta didáctica y como una institución sostenible y autónoma (Marengo et al., 2015).

Con respecto al sustento teórico, la experiencia de Barrancas se inscribió dentro de la arqueología pública y, con base en el componente interdisciplinario del proyecto, su enfoque fue abordado desde el marco conceptual de la sociología (Lucero et al., 2014). Con respecto a los proyectos llevados a cabo en el valle de Uco, se realizaron bajo el marco teórico de la arqueología social latinoamericana, la cartografía social y la propuesta pedagógica de la educación popular. Este trabajo implicó una construcción colectiva del conocimiento, un proceso continuo de reflexión sobre las prácticas y una herramienta fundamental que es la sistematización de experiencias.

Si bien ambos trabajos se abordaron desde distintos marcos teóricos, tienen ciertos aspectos que comparten: se valieron de experiencias de trabajo previo a la presentación de las convocatorias de extensión universitaria; trabajaron en red a partir de la articulación de distintas instituciones educativas y asociaciones vecinales; tuvieron cierta continuidad en la localidad; se brindaron talleres; y fueron interdisciplinarios. Finalmente, en ambos se realizaron trabajos de práctica arqueológica con la comunidad, con una preocupación por el uso y valoración de los bienes patrimoniales. Se tuvo como fin la concientización y protección del patrimonio local, el reconocimiento del entorno, su pasado precolonial y colonial, la conformación de la identidad comunal y la valoración de ciertas materialidades, costumbres y saberes. También fue central el carácter museográfico de ambos proyectos, donde el museo se mantuvo como el espacio o el resultado más directo de la interacción entre la academia y las comunidades. 
Teniendo en cuenta estos antecedentes a escala regional, pero considerando los debates que se vienen desarrollando en arqueología pública latinoamericana, finalmente consideramos y reflexionamos sobre cómo las PSE y el legado que retoman respecto a la educación popular y a la investigación acción pueden ayudar a replantear el rol de la arqueología y de sus futuros arqueólogos y arqueólogas. Para ello, en el siguiente apartado finalizamos nuestro artículo con un repaso de lo expuesto para considerar los desafíos que representan las PSE en la formación arqueológica universitaria regional.

\section{Reflexión: Ios desafíos que representan las PSE en el campo disciplinar arqueológico}

Propusimos evaluar las posibilidades y limitaciones implicadas en la aplicación de un programa de prácticas socioeducativas en el marco de la formación disciplinar en arqueología. Partiendo de la base de la dificultad supuesta en la problemática definición del rol de esta ciencia en la sociedad actual, a lo largo de este trabajo repasamos el legado histórico de la vinculación universidadcontexto. En este punto reconocimos los aportes de diversos pensadores y movimientos que permitieron modelar los conceptos centrales en esta práctica. Entre estos, destacamos la importancia del aprendizaje situado, involucrado en problemáticas concretas, así como multiactoral o permeable al diálogo con otros modos de conocimiento. Asimismo, es indisciplinado o no restringido a campos estancos y abiertos a la práctica de métodos múltiples y a la interacción con especialistas diversos. Observamos también el marco institucional actual que promueve la realización de estas prácticas y se señala la importancia de su implementación curricular.

Repasamos luego los antecedentes en la problematización de los vínculos entre la arqueología y sociedad, en la que observamos dos perspectivas principales. La primera se mantiene apegada al concepto clásico de extensión, en la que se entiende que su función social se encarga de transmitir conocimientos y concientizar sobre el cuidado del patrimonio. La segunda permite, a partir de la crítica del primer enfoque, el surgimiento de nuevos problemas y desafíos. En coincidencia con las discusiones dadas a este respecto a la universidad, la postura crítica reconoce la necesidad de situar la práctica en contextos de acción concretos y asociados a problemáticas sociohistóricas específicas. Con base en esto se destaca, en términos disciplinares más específicos, las posibilidades de intervención con fines de incorporación de historias marginales o incluyentes de actores estigmatizados. Asimismo, se enfatiza la participación en procesos que aboguen por la restitución de derechos o la ampliación de la justicia social.

No obstante estos aportes, reconocimos que las experiencias que incorporan de manera aplicada el acervo crítico son aún ejemplos aislados. De ello resulta 
que la vinculación arqueología-sociedad se mantiene en general dentro de los términos de la transferencia. Dicha situación es indicativa de lo dificultoso que resulta revertir inercias académicas en cuanto a modalidades de intervención social, en especial cuando las perspectivas que las sostienen continúan vigentes en los planos de la investigación y la formación. Pensándolo de esa forma, no resulta tan extraña esta dificultad. Pero a partir de este punto surge una potencialidad para las PSE que, incorporadas en la currículo, suponen una oportunidad para comenzar a revertir esta tendencia, al menos, desde la formación en la disciplina.

Por lo tanto, si consideramos el legado de procesos históricos constituyentes de la extensión en Argentina y en América latina, como fue la reforma universitaria de 1918 - las experiencias, conceptos y metodologías que proponían resquebrajar las lógicas transferencistas asentadas sobre una relación jerárquica entre docentes, estudiantes y actores sociales, así como las PSE con sus denominaciones afines - pueden presentar e impulsar desafíos a la formación disciplinar en arqueología. Entre estos desafíos remarcamos:

- Replantear la posición del arqueólogo y la arqueóloga como uno más en el entramado político, social, económico y cultural actual.

- Considerar la reconstrucción del pasado desde el presente y desde las múltiples voces que tienen conocimientos y saberes sobre el pasado.

- Crear e implementar metodologías que permitan la articulación entre el diálogo de saberes y las técnicas propiamente arqueológicas.

- Implementar espacios de formación curricular atentos a los contextos socioculturales actuales.

- Formar canales de comunicación que permitan el trabajo interdisciplinario en donde se integren especialistas de distintos campos con base en problemas transversales y en donde los estudiantes de arqueología sean partícipes activos.

- Revalorizar las experiencias locales en educación popular en donde estudiantes y docentes en arqueología puedan colaborar en la reconstrucción de la memoria de aquellos periodos de la historia que han sido fuertemente negados o invisibilizados, como, por ejemplo, el momento del cierre y eliminación de experiencias locales en educación popular durante y posterior a la dictadura militar.

- Reconsiderar el rol de los museos, las formas de exposición y las materialidades que se exhiben al considerar especialmente la posición de las 
poblaciones actuales en cuanto a estas materialidades y a los discursos que las dimensionan.

- Plantear alternativas que vayan más allá del espacio museográfico y que devengan justamente del diálogo entre estudiantes, docentes, organizaciones y actores sociales.

- Cuestionar y reflexionar sobre el rol político de futuros estudiantes en arqueología en los conflictos sociales, ambientales, de género, entre otros, y que se presentan fuertemente en nuestros contextos tanto regionales como latinoamericanos.

En suma, proponemos que la incorporación de las PSE en la formación en arqueología tiene el potencial de comenzar a reconstruir el rol de la disciplina en función de problemáticas sociales actuales concretas, así como de transformar esta reconstrucción en una dinámica que se actualice constantemente. Todo ello es posible siempre y cuando se desarrolle atendiendo el legado de experiencias y saberes acumulados en lo referente a vinculación social, tanto por la universidad como por los sectores críticos de la propia disciplina que buscamos presentar de manera sucinta en este artículo.

\section{Referencias}

Acuña, L., Zonana, M., Paiva, X., Guevara, M., Pérez, M., Quintas, F., Castillo, A. y Franchino, J. (2015. 24 de septiembre). Abordaje Zooarqueológico del Componente III agroalfarero de Agua de la Cueva (Precordillera de Mendoza). [ponencia]. XIV Congreso Nacional de Estudiantes de Arqueología, Córdoba, Argentina.

Acuto, F. (2019). Comentario al artículo: en contra del populismo reaccionario: hacia una nueva arqueología pública de Alfredo González-Ruibal, Pablo Alonso González Y Felipe Criado-Boado. Chungara, 51(1), 141-144. https://bit.ly/3rD47mq

Araujo, E., Tobar, V., Giannotti, S., Frías, C. y Castañar, K. (2014) Construyendo en la Arboleda: proyecto sobre valoración y uso social del Patrimonio Arqueológico. La Zaranda de ideas. Revista de Jóvenes Investigadores en Arqueología, 10(1), 66-74. https://dialnet.unirioja.es/servlet/articulo? codigo $=7728661$

Angelo, D. (2019). ¿Vox populi, voxdei? La urgencia de teorizar lo político y politizar lo teórico en arqueología. Chungara, 51(1), 145-149. https://bit.ly/39quOEH

Ayala, P. (2020). Arqueologías indígenas: una mirada desde el sur. Revista do Museu de Arqueologia e Etnologia, (34), 26-31.

Briones, C. (2005). Formaciones de alteridad: contextos globales, procesos nacionales y provinciales. En C. Briones (comp.), Cartografías argentinas. Políticas indigenistas y formaciones provinciales de alteridad (pp. 11- 43) Antropofagia.

Chiavazza, H. y V. Cortegoso (1997, 16-19 de junio). Arqueojuegos: taller de arqueología para niños. En el Área Fundacional de Mendoza [ponencia]. IX Congreso Nacional de Arqueología, Colonia, Uruguay. 
Leticia Saldi, Luis Mafferra, Vanina Terraza y Karina Castañar

Chiavazza, H. (2003). Arqueojuegos: Una experiencia educativa patrimonial con mucha tierra. Nueva Museología. Revista digital. https://nuevamuseologia.net/arqueojuegos-didactica-en-museos/

Consejo de Docencia, Extensión y Vida Estudiantil de la Universidad Nacional de Río Negro (2012, 2 de mayo). Resolución 018/12 sobre Dictar Reglamento de los Programas de Trabajo Social. https:// www.unrn.edu.ar/downloads/normativa-alumnos/Resolucion-CDEyVE-18-2012.pdf

Consejo Superior de la Universidad Nacional de Cuyo. (2016, 24 de octubre). Ordenanza 75/16-CS sobre actualización o creación de carreras de grado. http://ffyl.uncuyo.edu.ar/upload/ocs00752016.pdf

Consejo Directivo de la Facultad de Filosofía y Letras, Uncuyo. (2019, 11 de octubre). Ordenanza 55 sobre reforma al Plan de Estudio de la Carrera de Licenciatura en Arqueología. http://ffyl.uncuyo. edu.ar/upload/ord-05519cd-plan-de-estudio-licenciatura-en-arqueologia.pdf

Consejo Interuniversitario Nacional. (2009, 29 de septiembre). Acuerdo Plenario 711/09. Lineamientos para un programa de Fortalecimiento de la Extensión Universitaria en las Universidades Públicas Argentinas. https://bit.ly/31CaMTm

Consejo Interuniversitario Nacional (2012, 26 de marzo). Acuerdo Plenario 811/12. Plan Estratégico 2012-2015. https://bit.ly/3uiEwAO

Consejo Superior de la Universidad Autónoma de Entre Ríos, (2019, 29 de octubre). Resolución 128 sobre la Incorporación de las Prácticas Educativas Territoriales (PEN) en la formación de carreras de pregrado y de grado de la universidad. http://fcyt.uader.edu.ar/web/system/files/PET\%20 ORD.\%20N\%C2\%BA\%20128.pdf

Consejo Superior de la Universidad Nacional Del Centro de la Provincia de Buenos Aires (2018). Resolución 7381/18 sobre la Creación del Sistema de Prácticas Socioeducativas de la UNICEN, a implementarse en todas las unidades académicas.

Consejo Superior de la Universidad Nacional de Cuyo, (2016, 18 de febrero). Ordenanza 07 sobre los Lineamientos y ejes para la creación y/o actualización de carreras de pregrado y grado de la Universidad Nacional de Cuyo. http://ffyl.uncuyo.edu.ar/upload/ocs00072016.pdf

Consejo Superior de la Universidad de Buenos Aires (2010, 26 de mayo), Resolución 520 sobre la Aprobación en cuanto a la creación, en el ámbito de la Universidad, del Programa Prácticas Sociales Educativas. http://www.uba.ar/archivos_uba/2010-05-26_520.pdf

Consejo Superior de la Universidad Nacional de La Pampa, (2011, 16 de noviembre) Resolución 297 sobre la creación, en el ámbito de la Universidad Nacional de La Pampa, el Programa de "Practicas Comunitarias" (PPC). https://actosresolutivos.unlpam.edu.ar/static_ecs/media/uploads/pdf/4_7_2011_297_2lbCkBT.pdf

Consejo Superior de la Universidad Nacional de Mar del Plata, (2011). Ordenanza 1747 sobre la Incorporación de la obligatoriedad de las Prácticas Socio Comunitarias en los distintos planes de estudio.

Consejo Superior de la Universidad Nacional de Río Cuarto, (2009, diciembre) Resolución 322 sobre la Incorporación de prácticas socio-comunitarias a los planes de estudio de las carreras de la Universidad Nacional de Río Cuarto. https://www.unrc.edu.ar/unrc/planeamiento/docs/res322-09-creacionpsc.pdf

Dagnino, E. (2004). ¿Sociedade civil, participação e cidadania: de que estamos falando? En E. D. Mato (coord.), Políticas de Ciudadanía y Sociedad Civil en Tiempos de Globalización (pp. 95-110). Faces, Universidad Central de Venezuela. 
Degele, P. (2016). Patrimonio, política y áreas protegidas: el aporte de la arqueología pública al desarrollo regional (Provincia de Buenos Aires, Argentina). La zaranda de Ideas. Revista de Jóvenes Investigadores en Arqueología 14(2). 93-110. https://dialnet.unirioja.es/servlet/articulo?codigo $=7728637$

Deliyore-Vega, M. del R. (2018). Comunicación alternativa, herramienta para la inclusión social de las personas en condición de discapacidad. Revista Electrónica Educare, 22(1), 271-286. https:// dx.doi.org/10.15359/ree.22-1.13

Durán, V., Bauzá, M., Gómez, C. y Cortegoso, V. (1990). Situación de la enseñanza del pasado indígena en la Provincia de Mendoza. $1^{\circ}$ Encuentro Cultural Cuyano. p.107-109. Ediciones Culturales de Mendoza.

Durán, V., Bauzá, M., Gómez, C. y Cortegoso, V. (1991). Situación de la enseñanza del pasado indígena en la Provincia de Mendoza. En: Shincal 3, tomo 2. Actas del X Congreso Nacional de Arqueología Argentina, p. 222-228. Catamarca.

Dussel, E. (1973). Caminos de liberación latinoamericana II: teología de la liberación y ética. América Latina Libros.

Erreguerena, F. (2020). Las Prácticas Sociales Educativas en la Universidad Pública: una propuesta de definición y esbozo de coordenadas teóricas y metodológicas. Revista Masquedós 5(5). http://ojs. extension.unicen.edu.ar/index.php/masquedos/article/view/102

Facultad de Antropología Escolar de Mendoza. (2012, 25 de agosto). Comunicado de Prensa [publicación en Facebook]. https://bit.ly/3dcPLUG

Facultad Regional Mendoza, Universidad Tecnológica Nacional (1999). Taller de Orientación Universitaria. Ministerio de Cultura y Educación.

Fals Borda, O. y Rodríguez Brandao C. (1987). Investigación Participativa. La Banda Oriental.

Fals Borda, O. y Anisur MD. (1991) Acción y conocimiento: Rompiendo el monopolio con la IAP. Rahman.

Freire, P. (1984). ¿Extensión o comunicación? La concientización en el medio rural. Siglo XXI.

Freire, Paulo [1970] 1994. Pedagogía del oprimido. Siglo XXI.

Freire, Paulo [1967] 1999. Educação como prática da liberdade. Paz e Terra.

Freire, Paulo [1992] 2002 Pedagogía de la esperanza. Siglo XXI

Funari, P. (2002). A Arqueologia Pública na América Latina e seu contexto mundial. Fronteiras, 6(11), 87-96.

Funari, P. y Carvalho, A. (2014). Inclusión en la arqueología pública brasileña: apuntes sobre prácticas colaborativas. En M. Rivolta, M. Montenegro, L. Menezes y J. Nastri (eds.), Multivocalidad y activaciones patrimoniales en arqueología: perspectivas desde Sudamérica (pp. 193-216). Fundación de Historia Natural Félix de Azara. https://www.fundacionazara.org.ar/img/libros/multivocalidad.pdf

Giarracca, N. y Teubal, M. (2008). Del desarrollo agroindustrial a la expansión del 'agronegocio': el caso argentino. En B. Mançano Fernandes (org.), Campesinato e agronegócio na América Latina: a questão agraria atual (pp.139-164). Expressão Popular.

Giarracca, N. y Bidaseca (2001). Introducción. En N. Giarracca (coord.), La protesta social en Argentina. Transformaciones económicas y crisis social en el interior del país (pp. 19-40). Alianza. 
Leticia Saldi, Luis Mafferra, Vanina Terraza y Karina Castañar

Giarracca, N. (2002). Movimientos sociales y protestas en los mundos rurales latinoamericanos: nuevos escenarios y nuevos enfoques. Sociologias, (8), 246-274. https://doi.org/10.1590/S151745222002000200011

Gnecco, C. y Dias, A. S. (2015). Sobre arqueología de contrato. Revista de Arqueologia, 28(2), 3-19. https://revista.sabnet.org/index.php/SAB/article/view/425

González Jaramillo, L. (2008). Arqueología y formación profesional: esbozo para una cartografía histórica latinoamericana. En L. González Jaramillo (ed.), Arqueología en Latinoamérica: historias, formación académica y perspectivas temáticas (pp.187-286). Ediciones Uniandes.

González-Ruibal, A., Alonso González, P. y Criado-Boado, F. (2019). Respuesta a los comentarios del artículo: En contra del populismo reaccionario: hacia una nueva arqueología pública. Chungara, 51(1), 151-154. https://bit.ly/39mosGk

Haber, A. (2011). Nometodología payanesa: notas de metodología indisciplinada (con comentarios de Henry Tantalean, Francisco Gil García y Dante Angelo). Revista chilena de antropología, (23), 9-49. https://doi.org/10.5354/0719-1472.2011.15564

Haber, A. (2019). Comentario a "En contra del populismo reaccionario: hacia una nueva arqueología pública", de Alfredo González Ruibal, Pablo Alonso González y Felipe Criado Boado. Chungara, 51(1), 137-139. https://bit.ly/3u63zXM

Jackson, D., Troncoso, A., y Salazar, D. (2012). Hacia una crítica de la práctica de la arqueología social latinoamericana. En H. Tantaleán y M. Aguilar (comps), La arqueología social latinoamericana: de la teoría a la praxis (pp. 67-81). Universidad de Los Andes.

Jofre, I. C. (2020). Cuerpos/as que duelen. Cosmopolítica y violencia sobre cuerpos/as indígenas reclamados como ancestros/as warpes. Intersticios 9 (17), 73-100. https://revistas.unc.edu.ar/index. php/intersticios/article/view/28908

Laclau, E. y Mouffe, Ch. (2011). Hegemonía y estrategia socialista. Hacia una radicalización de la democracia. Fondo de Cultura Económica.

Lazzari, A., Oldani, K., Añon Suárez, M., Pepe, F. M., Endere, M. L., Gustavsson, A., y Rodríguez, M. E. (2011). Reclamos, restituciones y repatriaciones de restos humanos indígenas: cuerpos muertos, identidades, cosmologías, políticas y justicia. Corpus. Archivos virtuales de la alteridad americana, 1(1). https://doi.org/10.4000/corpusarchivos.962

Lischetti, M. (2013). Universidades Latinoamericanas. Compromiso, praxis e innovación. Editorial de la Facultad de Filosofía y Letras. Universidad de Buenos Aires.

Lischetti, M., Paoletta H. y Sander J. (2019). El proceso instituyente de las prácticas socioeducativas territorializadas. Un esbozo de investigación: aportes, antecedentes, debates y desafíos. Redes de Extensión, 5, 51-66. http://revistascientificas.filo.uba.ar/index.php/redes/article/view/6162

Londoño, W. (2011). Los estudios de herencia cultural como una alternativa a la arqueología científica oa la patrimonialización de los dioses: del paradigma de la ruptura al de la continuidad. Jangwa Pana, 10(1), 97-111. http://revistas.unimagdalena.edu.co/index.php/jangwapana/article/view/74

Londoño, W. (2016). Arqueología por contrato y nuevos contratos arqueológicos. Jangwa pana, 15(1), 117-128. https://doi.org/10.21676/16574923.1756 
Londoño, W. (2019). Comentarios a: González-Ruibal, A., P. Alonso González Y F. Criado-Boado 2019. En contra del populismo reaccionario: hacia una nueva arqueología pública. Chungara, 51(1), 125-128. https://bit.ly/3m3edf7

Lorenzo, J., Lumbreras, L., Matos, E., Montané, J. y Sanoja, M. (1979). Hacia una arqueología social. (Reunión en Teotihuacan, octubre de 1975). Nueva Antropología, 3(12), 65-92. https://revistas-colaboracion.juridicas.unam.mx/index.php/nueva-antropologia/article/view/15120/13489

Lucero, N., Peroni, M., Yebra, L., Ayala, A., Estrella, D., Durán, V., Marsh, E., Frigolé, C., Moyano, R., Navarro, D., Sergo, F. y Acuña, L. (2014, 17 de septiembre). El rol de la extensión en el desarrollo local comunitario: El caso de una experiencia de Arqueología pública en la comunidad de Barrancas Mendoza-Maipú [ponencia]. VI Congreso Nacional de Extensión Universitaria, Rosario, Argentina. https://bit.ly/2OapTjW

Macchiarola, V. (2016): Prácticas socio-comunitarias en la Universidad Nacional de Río Cuarto. Recorridos, sentidos y políticas. En A., Vogliotti, S. Barroso y D. Wagner (comps.), 45 años no es nada para tanta historia. Trayectorias, memorias y narratorias sobre la UNRC desde la diversidad de voces (pp. 503-512). Unirío.

Marengo, M., Guardia, N., Francalancia, F., Bontorno, E., Porta, V., Araujo, E., Giannotti, S., Hernandez, F. y Castañar, K. (2015, 23 de septiembre) Valoración y uso social del Patrimonio cultural en el sur mendocino. El caso del Museo regional Comunitario El Diamante [ponencia]. XIV Congreso Nacional de Estudiantes de Arqueología, Córdoba, Argentina.

Montenegro, M. (2012). Arqueología en la escuela: experiencias en el sector septentrional del Noroeste argentino. Chungara, Revista de Antropología Chilena, 44(3), 487-498. https://bit.ly/3uixmwP

Montenegro, M., Zabala, M. E. y Pupio, A. (2019, 17 de julio). Arqueología pública iuniversalidad o pluri-versalidad epistemológica? [simposio]. XX Congreso Nacional de Arqueología Argentina, Córdoba, Argentina. http://www.congresoscnaa.org/

Ortiz-Riaga, M. C. y Morales-Rubiano M. E. (2011). La extensión universitaria en América Latina: concepciones y tendencias. Educación y Educadores, 14(2): 349-366. https://bit.ly/3rxNwk1

Ortiz, M. y Borjas, B. (2008). La investigación acción participativa: aporte de Fals Borda a la educación popular. Espacio Abierto, 17(4), 615-627 https://produccioncientificaluz.org/index.php/espacio/ article/view/1365

Piazzini Suárez, C.E. (2014). Conocimientos situados y pensamientos fronterizos: una relectura desde la universidad. Geopolítica(s), 5(1), 11-33. https://doi.org/10.5209/rev_GEOP.2014.v5.n1.47553

Poder Legislativo, República de Argentina. (1995, 7 de agosto). Ley de Educación Superior 24521/1995. Boletín Oficial n. ${ }^{\circ}$ 28.204. https://bit.ly/2PPPdvM

Poder Legislativo, República Argentina (2006, 14 de diciembre). Ley 26.206. Ley de Educación Nacional. Boletín Oficial n. ${ }^{\circ}$ 31.62. https://www.argentina.gob.ar/educacion/validez-titulos/glosario/ley26206

Prensa Gobierno de Mendoza. (2013, 28 de agosto). Colocaron una placa en el lugar donde funcionó la Facultad de Antropología Escolar. Mendoza Gobierno. https://bit.ly/3wa4sAB

Presidencia de la República de Argentina (2020, 20 de marzo). Decreto 297/2020. Boletín Oficial n. ${ }^{\circ}$ 15887/20. https://bit.ly/3wjpgpb

Ramundo, P. S. (2008). Medio siglo de formación académica en arqueología: avances y cuentas pendientes. La Zaranda de Ideas, (4), 141-146. https://dialnet.unirioja.es/servlet/articulo?codigo $=7728686$ 
Leticia Saldi, Luis Mafferra, Vanina Terraza y Karina Castañar

Romero, A., Ajata, R., Espinosa, G. y Briones, L. (2004). Arqueología pública y comunidades rurales: un proceso de puesta en valor en el valle de Codpa, región de Tarapacá. Boletín Museo Gabriela Mistral de Vicuña 6, 42-63. https://www.mgmistral.gob.cl/634/articles-23078_archivo_01.pdf

Salazar, D., Urrea-Navarrete, J., Escobar, M., Andrade, P., Muñoz, M., Maldonado, C., Torres, R. y Vargas, K. (2020, 8 de junio). Arqueología y educación formal en la costa de Taltal-Paposo: reflexiones sobre "arqueología pública". Chungara. Epub. https://dx.doi.org/10.4067/\$0717-73562020005000801

Salerno, V. (2013). Arqueología pública: reflexiones sobre la construcción de un objeto de estudio, con comentarios de Daniella Jofré, Lúcio Mesezes y Henry Tantalean. Revista Chilena de Antropología, (27), 7-37. https://doi.org/10.5354/0719-1472.2013.27350

Silva, F. A. (2015). Arqueologia de Contrato e Povos Indígenas: reflexões sobre o contexto brasileiro. Revista de Arqueologia, 28(2), 187-201. https://revista.sabnet.org/index.php/SAB/article/view/435

Sousa Santos, B. de (2010). La universidad en el siglo XXI. Para una reforma democrática y emancipadora de la universidad. Extensión Universitaria / Trilce.

Sousa Santos, B. de (2012): De las dualidades a las ecologías. Red Boliviana de Mujeres Transformando la Economía REMTE.

Svampa, M. (coord.) (2008): Cambio de época. Movimientos sociales y poder político. Clacso; Siglo XXI.

Tantaleán, H. (2019). Nunca fuimos apolíticos: Comentarios a "En contra del populismo reaccionario: Hacia una nueva arqueología pública". Chungara, 51(1), 133-135. https://bit.ly/3w9fTs5

Tommasino, H. y Cano, A. (2016). Modelos de extensión universitaria en las universidades latinoamericanas en el siglo XXI: tendencias y controversias. Universidades, 66(67), 7-24. http://udualerreu. org/index.php/universidades/article/view/395

Tommasino, H. y Rodríguez N. (2013). Tres tesis básicas sobre extensión y prácticas integrales en la Universidad de la República, bases y fundamentos. En M. Lischetti (coord.) Universidades Latinoamericanas. Compromiso, praxis e innovación (pp. 83-102). Editorial de la Facultad de Filosofía y Letras de la Universidad de Buenos Aires.

Tommasino, H., Cano A., Castro D., Santos C. y Stevenazzi, F. (2010). De la extensión a las prácticas integrales. En Rectorado, Universidad de la República (org.), Hacia la reforma universitaria. La extensión en la transformación de la enseñanza: espacios de Formación Integral (pp. 25-32). Udelar.

Universidad Nacional de Cuyo. (2013). Plan Estratégico 2021.

Ugalde, M. F. (2019). Arqueología bajo la lupa Queer: una apuesta por la multivocalidad. Revista Arqueología Pública, 13(1 [22]), 135-154. https://doi.org/10.20396/rap.v13i1.8654833

Vargas, I. (1995, mayo). La Arqueología Social: un paradigma alternativo al angloamericano [ponencia]. Reunión de la Asociación Americana de Arqueología, Minneapolis, Estados Unidos. https://www. ifch.unicamp.br/eha/chaa/rhaa/downloads/Revista\%208\%20-\%20artigo\%206.pdf

Vargas, I (2006). La conservación del patrimonio histórico. Nuevas propuestas desde la arqueología a la luz de la democracia participativa y protagónica. Boletín Antropológico, 24(67), 311-334. https:// www.redalyc.org/articulo.oa?id $=71206706$

Vazquez, G. (2016). La labor antropológica en el campo de las políticas de extensión universitaria. Anthropologica, 34(36), 9-29. http://dx.doi.org/10.18800/anthropologica.201601.001 
Wagner, L. (2014). Conflictos socioambientales. La megaminería en Mendoza, 1884-2011. Universidad Nacional de Quilmes

Zabala, M., Roura, I. y Fabra, M. (2006) Educar en patrimonio: educar en valores. Propuesta didáctica para interpretar el patrimonio en el aula. Museo de Antropología, Facultad de Filosofía y Humanidades, Universidad Nacional de Córdoba.

Zabala, M. y Fabra, M. (2012). Estrechando vínculos entre "comunidades" en torno al patrimonio arqueológico. Las prácticas extensionistas desde un programa de arqueología pública. Revista Arqueología Pública, 6(6), 39-53. https://doi.org/10.20396/rap.v6i1.8635733 